\title{
Temperature Control Feedback Loops for the Linac Upgrade Side Coupled Cavities at Fermilab
}

\author{
Jim Crisp \\ Fermi National Accelerator Laboratory \\ P.O. Box 500 \\ Batavia, Illinois 60510
}

October 25, 1990 


\title{
Fermilab
}

\section{TEMPERATURE CONTROL FEEDBACK LOOPS FOR THE LINAC UPGRADE SIDE COUPLED CAVITIES AT FERMILAB}

\author{
by Jim Crisp
}

$10 / 25 / 90$

\section{INTRODUCTION:}

The linac upgrade project at Fermilab will replace the last 4 drift-tube linac tanks with seven side coupled cavity strings. This will increase the beam energy from 200 to $400 \mathrm{MeV}$ at injection into the Booster accelerator.

The main objective of the temperature loop is to control the resonant frequency of the cavity strings. A cavity string will consist of 4 sections connected with bridge couplers driven with a $12 \mathrm{MW}$ klystron at $805 \mathrm{MHz}$. Each section is a side coupled cavity chain consisting of 16 accelerating cells and 15 side coupling cells. For the linac upgrade, 7 full cavity strings will be used. A separate temperature control system is planned for each of the 28 accelerating sections, the two transition sections, and the debuncher section.

The cavity strings will be tuned to resonance for full power beam loaded conditions. A separate frequency loop is planned that will sample the phase difference between a monitor placed in the end cell of each section and the if drive. The frequency loop will control the set point for the temperature loop which will be able to maintain the resonant frequency through periods without beam or if power. The frequency loop will need the intelligence required to determine under what conditions the phase error information is valid and the temperature set point should be adjusted.

This paper will discuss some of the reasons for temperature control, the implementation, and some of the problems encountered. An appendix contains some useful constants and descriptions of some of the sensor and control elements used.

\section{REQUIREMENTS:}

The side coupled cavities will have a resonant frequency 4 times that of the current linac, about $805 \mathrm{MHz}$, and an unloaded $\mathrm{Q}$ of 20,000 . With 16 accelerating and 15 coupling cells, there will be 31 possible coupled cavity modes per section. Because the end cells form a "full" termination, the modes for a string with $N$ cells will occur when the string is $\pi(i+1) N /(N+1)$ radians long, for $\mathrm{i}=0,1, \ldots, \mathrm{N}-1$. With the four sections connected through three bridge couplers to form a cavity string, there will be $4 \times 31+3 \times 3=133$ modes. This assumes that all coupling 
cells including those to the bridge couplers are identical, and that all accelerating cells and bridge coupling cells are the same.

The operating mode chosen is the $\pi / 2$ mode, so called because of the $\pi / 2$ phase difference per cell. Bill Miller has the formidable task of identifying the $\pi / 2$ mode from the 133 possibilities. This mode forms a standing wave within the string which has voltage maxima at accelerating cells and minima at coupling cells. The physical separation between the accelerating cells is carefully calculated so that the beam flight time and the $\pi$ phase difference between accelerating cells provide uniform acceleration along the linac. The $\pi / 2$ mode is selected because of the efficiency with which it couples to the beam and its unique stability properties with beam loading.

For a cavity constructed of a single metal, the percentage change in resonant wavelength will be equal to the percentage change in linear dimension which is proportional to temperature. The thermal expansion of copper is about $16.5 \mathrm{ppm} /{ }^{\circ} \mathrm{C}$, according to "Reference Data for Radio Engineers". This depends on the purity of the copper, its crystalline structure, and temperature. A full cavity section had a measured temperature dependance of $-14.3 \mathrm{KHz} /{ }^{\circ} \mathrm{C}$, or $17.8 \mathrm{ppm} /{ }^{\circ} \mathrm{C}$ of $805 \mathrm{MHz}$.

Several things happen as the coupled cavity system becomes mistuned. For the $\pi / 2$ mode, the stopband will become nonzero providing phase and amplitude errors along the cavity chain. This will limit the net accelerating voltage by requiring the cell with the largest amplitude to have less than the breakdown voltage. The $Q$ and cavity impedance will also be reduced requiring more power from the klystron. The design specification for the low level system limits the phase error to $.5^{\circ}$ and the amplitude error to $.5 \%$. Presumably this is the net voltage and phase along one string of four sections. The amplitude and phase loops will be able to maintain those values within the one cell being monitored but the net voltage and phase of the four section string could still be adversely affected by temperature variations.

Four 16 accelerating cell sections will be connected with bridge couplers and driven with a single klystron. If the cavity resonant frequency deviates from the drive frequency, power will be reflected from the cavity, causing standing waves within the waveguide. The klystron tube design specification requires it to withstand a standing wave ratio, or vswr, of up to $1.5: 1$ at the $12 \mathrm{MW}$ power level. The limit is believed to be the breakdown voltage of the ceramic window at the output of the klystron. The WR975 waveguide is rated for $28.7 \mathrm{MW}$ at $805 \mathrm{MHz}$, or a vswr of 3.41 at $12 \mathrm{MW}$. Because the cavity impedance could be inductive or capacitive, when the drive frequency is low or high respectively, it is impossible to trim the waveguide length to ensure a voltage minima at the tube. Table 1 below provides the vswr versus frequency and temperature, assuming a parallel RLC impedance versus frequency curve and a $14.3 \mathrm{KHz} /{ }^{\circ} \mathrm{C}$ temperature dependance.

$$
\frac{Z}{Z_{o}}=\frac{1}{1+j 2 Q \frac{\delta f}{f_{o}}} \quad, \quad \delta f=f-f_{o}
$$




$$
\mathrm{K}=\frac{\frac{\mathrm{Z}}{\mathrm{z}_{\mathrm{o}}}-1}{\frac{\mathrm{Z}}{\mathrm{z}_{\mathrm{O}}}+1}
$$

reflection coefficient

$$
\text { vswr }=\rho=\frac{1+|\mathrm{K}|}{1-|\mathrm{K}|}=\frac{\sqrt{1+\left(\frac{f_{O}}{\mathrm{Q} \delta \mathrm{f}}\right)^{2}}+1}{\sqrt{1+\left(\frac{f_{\mathrm{O}}}{\mathrm{Q} \delta \mathrm{f}}\right)^{2}}-1}
$$

$$
V_{\text {ratio }}=\frac{2 \rho}{\rho+1}
$$

Table 1.

\begin{tabular}{llll} 
vswr & Vratio & $\delta f$ & temp \\
\hline 1 & 1 & $0 \mathrm{KHz}$ & $0{ }^{\circ} \mathrm{C}$ \\
1.22 & 1.10 & 4 & .28 \\
1.49 & 1.20 & 8 & .56 \\
1.81 & 1.29 & 12 & .84 \\
2.18 & 1.37 & 16 & 1.12 \\
2.62 & 1.45 & 20 & 1.40 \\
5.83 & 1.71 & 40 & 2.80
\end{tabular}

Beam loading on the cavity will be significant. According to the design report, the 12 MW capacity of the klystron is allocated according to table 2 below.

Table 2.

\begin{tabular}{ll}
$7.1 \mathrm{MW}$ & Copper loss \\
2.0 & $50 \mathrm{~mA}$ beam, (average) \\
$\frac{2.9}{12.0}$ & control / reserve \\
\hline
\end{tabular}

As shown in figure 1, the vector sum of the drive current with beam, Id2, and the beam image current, -Ib, must equal that current which would produce the correct accelerating voltage in the cavity without beam, Id1. In addition, the dot product of Id2 with Vcav must be $9.1 / 7.1$ times larger than the dot product of Id1 and Vcav in order to obtain the correct increase in power. Using $\phi a$ to represent the accelerating phase and Pr to indicate the ratio of total power to copper loss, the relative magnitude and angle of Id 2 can be found.

$$
\begin{aligned}
& P_{r}=\frac{9.1}{7.1}, \quad \phi_{a}=32^{\circ} \\
& I_{d 1}+I_{b} \cos \phi_{a}=P_{r} I_{d 1}
\end{aligned}
$$




$$
\begin{aligned}
& I_{b} \cos \phi_{a}=\left(P_{r}-1\right) I_{d 1} \\
& I_{b} \sin \phi_{a}=\left(P_{r}-1\right) I_{d 1} \tan \phi_{a} \\
& \left|I_{d 2}\right|=\left|I_{d 1}\right| \sqrt{P_{r}^{2}+\left(P_{r}-1\right)^{2} \tan ^{2} \phi_{a}}=1.294\left|I_{d 1}\right| \\
& \left\lfloor d 2=\theta_{t}=\arctan \left[\frac{\left(P_{r}-1\right) \tan \phi_{a}}{P_{r}}\right]=7.82^{\circ}\right.
\end{aligned}
$$

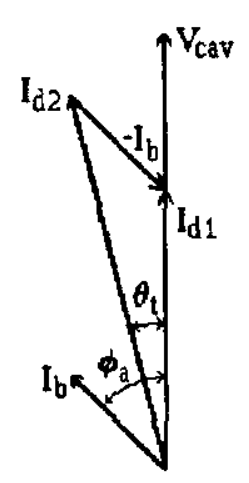

Figure 1. Vector diagram of cavity voltage, if drive current, and beam current.

To obtain the correct tuning angle, $\theta \mathrm{t}$, the cavity resonant frequency must be $2.8 \mathrm{KHz}$ below the drive frequency which can be accomplished by running the cavity $.2^{\circ} \mathrm{C}$ warmer. The remaining resistive change could be corrected, for one beam current, by adjusting the waveguide to cavity string matching. At present this match is adjusted with the size of the iris in the waveguide to bridge coupler cell.

The standing wave ratio caused by beam loading can be calculated from the ratio of cavity impedance with beam to impedance without beam. Since the cavity voltage is the same with or without beam, the ratio of impedance is equivalent to the ratio of currents.

$$
\begin{aligned}
& \frac{\mathrm{Z}_{\mathrm{b}}}{\mathrm{Z}_{\mathrm{o}}}=\frac{\mathrm{I}_{\mathrm{d} 1}}{\mathrm{~L}_{\mathrm{d} 2}}=.773 \angle-7.82^{\circ} \\
& \mathrm{K}=\frac{\frac{\mathrm{Z}_{\mathrm{b}}}{\mathrm{Z}_{\mathrm{o}}}-1}{\frac{\mathrm{Z}_{\mathrm{b}}}{\mathrm{Z}_{\mathrm{o}}}+1}=.145 \angle-152.4^{\circ}
\end{aligned}
$$




$$
\mathrm{vswr}=\frac{1+|\mathrm{K}|}{1-|\mathrm{K}|}=1.34
$$

If the waveguide to cavity matching is tuned for beam loading, the vswr will be $1.34: 1$ without beam. The $Q$ of the system will be reduced when beam is present by a factor of $.773 \cos \theta t$, from 20,000 to about 15,000 . Beam loading will not change the amount of power flowing into the copper and thus will not create a transient in the cooling system, however.

When rf power is applied to the cavity, 200 watts per cell flows through the copper into the cooling water. The thermal resistance of the copper path results in a temperature gradient within the cell. An analysis of the heat flow using ANSYS was performed by Jim Olson and Terry Anderson indicating that at 200 watts/cell, the nose cones in the accelerating cells will be $2.52^{\circ} \mathrm{C}$ warmer than the cooling water. The cell geometry and the distribution of power were supplied by Tom Jurgens. A full cavity section was measured to have a frequency deviation of $35.3 \mathrm{KHz}$ for 200 watts/cell of $\mathrm{rf}$ excitation, $\left(35.3 \mathrm{KHz} / 2.52^{\circ} \mathrm{C}=14.0 \mathrm{KHz} /{ }^{\circ} \mathrm{C}\right)$.

When the rf power is turned on abruptly, the resonant frequency of the cavity string approaches a new steady state value exponentially, with a time constant of 24 seconds. If one half of the rf power is dissipated on the nose cones, then an equivalent model is 5.4 pounds of copper connected through a thermal resistance of 100 watts $/ 2.52{ }^{\circ} \mathrm{C}$ to the remainder of the thermal mass. The thermal mass of one 16 accelerating cell section, (1700 pounds of copper and 36 gallons of water), is $872 \mathrm{KJ} /{ }^{\circ} \mathrm{C}$. The thermal mass of 16 nose cones is only about $15.2 \mathrm{KJ} /{ }^{\circ} \mathrm{C}$.

The $-35.3 \mathrm{KHz}$ resonant frequency shift caused by the if power turning on could be corrected with a temperature change of $-2.46^{\circ} \mathrm{C}$. It would require $89 \mathrm{KW}$ of cooling for 24 seconds to change the temperature of the $872 \mathrm{KJ} /{ }^{\circ} \mathrm{C}$ thermal mass by this amount. To help put things in perspective, one Burger King "whopper" contains about 628 kilocalories which could heat the system by $3.0^{\circ} \mathrm{C}$. The peak rf power per accelerating cell is about $111 \mathrm{KW}$. During each $120 \mu \mathrm{sec}$ long gradient pulse, the nose cone temperature will rise by $.0070{ }^{\circ} \mathrm{C}$ and the resonant frequency will decrease by $98 \mathrm{~Hz}$.

If the cavity strings are kept at the temperature which provides the correct resonant frequency with nominal power, then the resonant frequency will be $35.3 \mathrm{KHz}$ too low with no rf power applied. This will result in a vswr of $4.9: 1$, or a $3.7 \mathrm{MW}$ power limit, when the power is initially turned on. The if power could be programmed on while limiting the peak waveguide voltage. As the cavity warms up, the frequency error and vswr will decrease and the if power can be increased further. Tom Owens used ACSL to obtain a power program which limits the maximum waveguide voltage to that obtained with $12 \mathrm{MW}$ and a vswr of $1.5: 1$, shown in figure 2. This model assumes a frequency shift of $-11 \mathrm{KHz} / \mathrm{KW}$ with a 24 second $1 / \mathrm{e}$ time constant, a temperature dependance of $-14.3 \mathrm{KHz} /{ }^{\circ} \mathrm{C}$, and allows a maximum power of $12 \mathrm{MW}$. The cavity could reach the nominal resonant frequency in about 39 seconds. This process could be implemented with a control loop in the local computer which monitors the reverse power and controls the klystron output during turn on, similar to the existing linac. Maintaining the cavities at a higher temperature to compensate for beam loading would reduce the vswr at turn on and shorten the required time. 

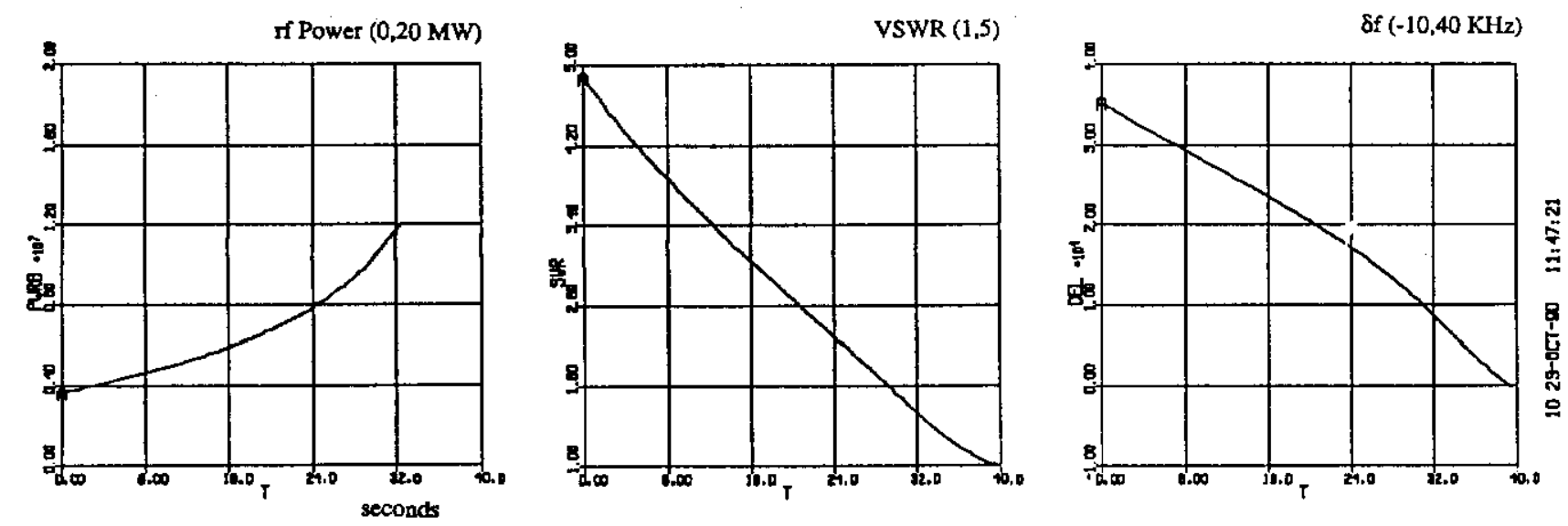

Figure 2. RF power, VSWR, and frequency error versus time during turn on.

Another power on approach would be to adjust the drive frequency to resonance during turn on. This would allow the application of full power immediately, which would provide a faster warm up time. A simple cavity phase detector could be used to drive a VCO much like the system designed by Quentin and Cordon Kerns for the $2 \mathrm{MW}$ test stand. Because the rf is on only $120 \mu \mathrm{sec}$ out of $66.7 \mathrm{msec}$, Tom Owens has suggested a system which time shares one high quality frequency generator rather than use 7 VCOs. During cavity warm up, the rf pulse would occur between normal accelerating pulses. The warm up generator could be phase locked to the 7 cavity strings at 7 separate times using simple feedback loops implemented in the local computers. The frequency generator could be used to produce the nominal accelerating frequency as well, but this would preclude the use of a tuned distribution line as suggested by Quentin Kerns. This system would allow changing the if frequency to measure such things as cavity $\mathrm{Q}$ or the resonant frequencies of neighboring modes which can be used to determine the stopband of the $\pi / 2$ mode.

The waveguide connecting the klystron to the cavity will be carefully trimmed to be an integer number of $1 / 2$ wavelengths long. For an ideal transmission line, this will reproduce the cavity impedance at the klystron output. When a spark occurs in the cavity, there will be an impedance minimum at the klystron. The change in amplitude and phase with frequency of the cavity voltage with respect to the klystron beam current can be estimated with the parallel RLC impedance equation. The maximum allowable vswr of 1.5:1 occurs for a frequency error of 8 $\mathrm{KHz}$ and will generate an amplitude error of $7.1 \%$ and a phase error of $21.7^{\circ}$. If all four sections have the same temperature change, an $8 \mathrm{KHz}$ shift would be generated with a $.56{ }^{\circ} \mathrm{C}$ error. Since the low level feedback system will be able to compensate for these magnitude and phase errors, the temperature regulation is only required to maintain the vswr limit. With the $+.2^{\circ} \mathrm{C}$ beam loading compensation, the temperature must be held to within +.36 to $-.56{ }^{\circ} \mathrm{C}$ of the nominal beam loaded temperature. The cooling system was designed to have better than $\pm .05^{\circ} \mathrm{C}$ temperature regulation in the steady state. This corresponds to a frequency error of $\pm 720 \mathrm{~Hz}$ or a vswr of 1.04:1. 


\section{COOLING SYSTEM:}

The cooling system, as shown in figure 3, was designed by John Satti. It is desired to have independent temperature control of the 28 accelerating sections plus the transition and debuncher sections. To accomplish this, each section will have a cooling skid external to the linac enclosure. A pump will circulate about $40 \mathrm{gpm}$ of LCW water between the cooling skid and the cavity. The temperature of the circulating water and cavity will be maintained by controlling the amount of chilled water allowed into the system. The cavity is expected to run nominally at room temperature, about $25^{\circ} \mathrm{C}$. With a chilled water temperature of $11^{\circ} \mathrm{C},(25-$ $11) / 3.814=3.67 \mathrm{KW}$ for each gpm of chilled water flow will be extracted. The $7.1 \mathrm{MW}$ peak $\mathrm{rf}$ power per klystron is equivalent to $3.2 \mathrm{KW}$ of average power per section. The water pump will add about $1.7 \mathrm{KW}$ of power. With the if on, the nominal chilled water flow will be $1.4 \mathrm{gpm}$ or about $.5 \mathrm{gpm}$ with the rf off.

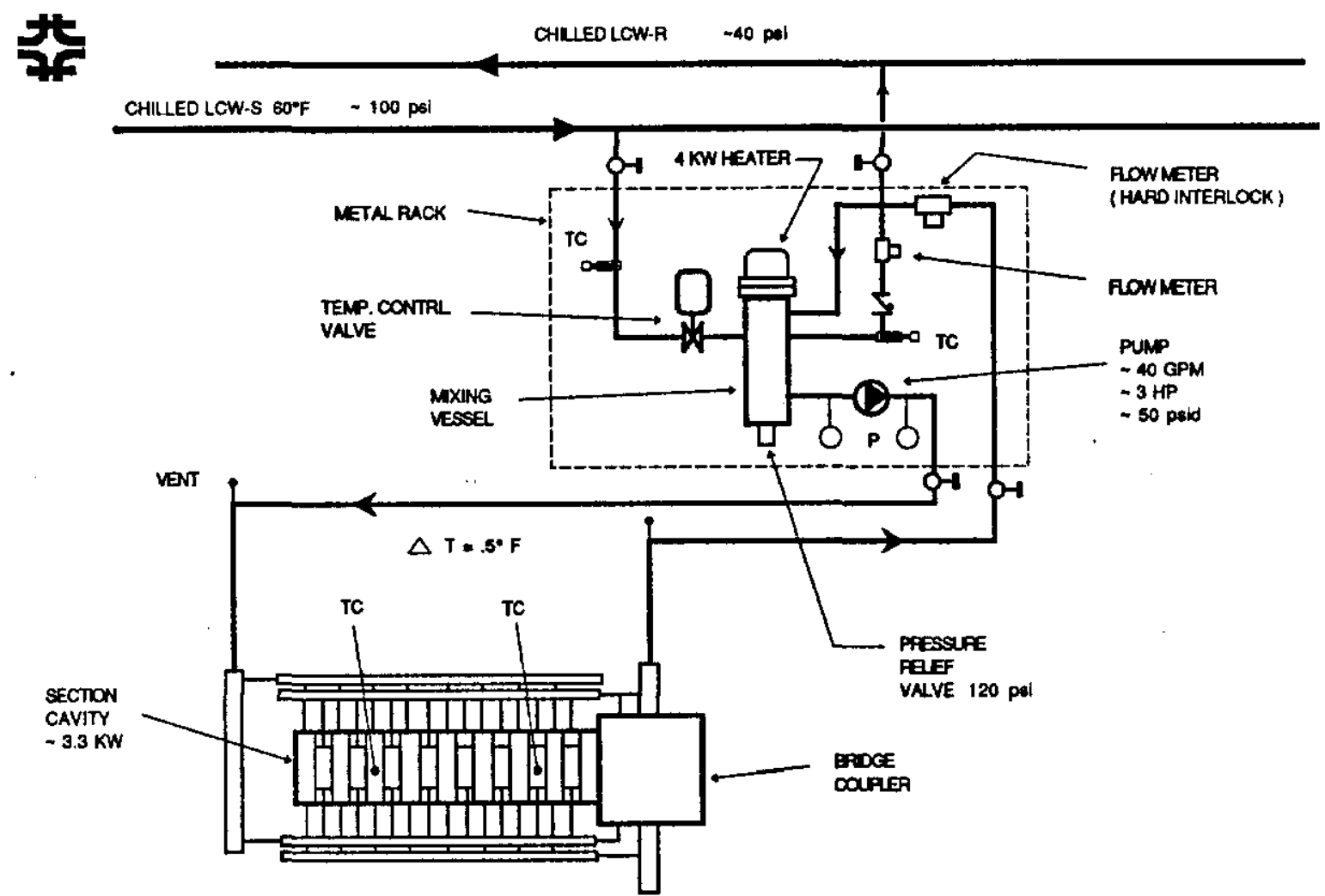

Figure 3. Schematic of cavity temperature control system. 
The cooling skids will be up to 95 feet from the cavities. The 190 feet of 2 inch pipe will contain 31 gallons of water. With an additional 5 gallons to fill the cavity cooling tubes and the water skid, the system capacity becomes 36 gallons. At $40 \mathrm{gpm}$, this amount of water will require 54 seconds to make one loop through the system. This delay will limit the closed loop bandwidth and complicate the use of feedforward. The heat capacity of 36 gallons of water is $574 \mathrm{KJ} /{ }^{\circ} \mathrm{C}$ compared to $298 \mathrm{KJ} / \mathrm{C}$ for the 1700 pounds of copper in one section. The heat capacity determines how much energy will be required to change the cavity temperature, 872 $\mathrm{KW}$ for 1 second would provide a $1^{\circ} \mathrm{C}$ change. If the cooling were turned off, the temperature would increase at the rate of $.0057^{\circ} \mathrm{C} / \mathrm{sec}$ from the $4.9 \mathrm{KW}$ of rf and pump power. Fortunately the cavities will run at constant temperature!

From the appendix we see some interesting properties of water. It has about 10 times the heat capacity and 650 times the thermal resistance of copper. The large heat capacity makes water an efficient way to carry heat, or cooling, to the cavities. The thermal resistance makes it difficult to transfer heat between the water and the copper. If the water flow through the cooling tubes on the cavity is slow, very little mixing will occur and a large temperature gradient will develop between the flowing water and the tube wall. Special, internally ridged, copper tubing was used on the cavity along with a high flow rate to insure turbulent flow. The flow rate is limited to reduce wear on the copper tubes. From available literature, the tubing used is expected to have a film coefficient of 200 watts $/{ }^{\circ} \mathrm{C}$ per water path. Recent measurements indicate 400 watts $/{ }^{\circ} \mathrm{C}$ per water path. I do not have confidence in either figure at this time. The time constant formed with the film coefficient can be significant as shown below.

$$
\frac{298 \mathrm{KJ}}{1{ }^{\circ} \mathrm{C}} \frac{1000 \mathrm{~J}}{\mathrm{KJ}} \frac{1^{\circ} \mathrm{C}}{200 \text { watt }} \frac{1}{17 \text { water paths }}=87.6 \text { seconds }
$$

Radiation and convection from a 16 accelerating cell section, cooling skid, and 98 feet of PVC pipe was measured to be about 60 watts $/{ }^{\circ} \mathrm{C}$ for variations of less than $10^{\circ} \mathrm{C}$. Using numbers for radiation and convection for a horizontal cylinder, the thermal resistance was estimated as 13 watts $/{ }^{\circ} \mathrm{C}$ for the cavity section and 23 watts $/{ }^{\circ} \mathrm{C}$ for the $\mathrm{PVC}$ pipe for a total of 36 watts $/{ }^{\circ} \mathrm{C}$. In the linac upgrade, 190 feet of 2 inch copper pipe will be used to connect the cavity section to the cooling skid. This will increase the estimated losses from radiation and convection to about 100 watts $/{ }^{\circ} \mathrm{C}$. This depends on the movement of air around the cavity and cooling system and is a complicated function of temperature. Depending on the cavity operating temperature, it may be necessary to insulate the copper pipes which link the cooling skid to the cavity section.

\section{CONTROL THEORY:}

A simple model, applicable to the cavity cooling system, is shown in figure 4 . It consists of a container, with water flowing through it, that retains a constant volume. If we assume that the inlet water instantaneously and completely mixes in the volume, then the thermal mass C will be at the outlet temperature Tout. The change in outlet temperature will be equal to the time 
integral of the net power flowing into the volume divided by its thermal capacitance. Assume at time $t=0$ the system is in steady state, the temperature of thermal mass $C$ is $T o=$ Tout $=$ Tin, and that Pcool represents the power removed with water flow.

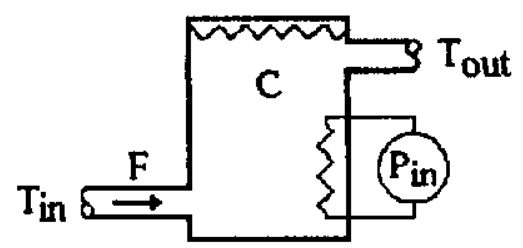

Figure 4. Simple model of cavity temperature control system.

$$
\frac{1}{C} \int_{0}^{t} P_{\text {in }}-P_{\text {cool }} d t=T_{\text {out }}-T_{0}
$$

Or, after taking the derivative, multiplying by $\mathrm{C}$, and realizing $\mathrm{T}_{\mathbf{0}}$ is constant, equation 2 can be used.

$$
P_{\text {in }}-P_{\text {cool }}=C \frac{d}{d t} T_{\text {out }}
$$

equation 2

Here, Pin is the amount of power being applied to the thermal mass of the system. Letting $A=$ $3.814 \mathrm{gpm}^{\circ} \mathrm{C} / \mathrm{KW}$, Pcool can be expressed with equation 3 which can be substituted into equation 2 to make equation 4.

$$
\begin{aligned}
& P_{\text {cool }}=\left(T_{\text {out }}-T_{\text {in }}\right) \frac{F}{A} \\
& \frac{d}{d t} T_{\text {out }}+\frac{F}{A C} T_{\text {out }}=\frac{1}{C} P_{\text {in }}+\frac{F}{A C} T_{\text {in }}
\end{aligned}
$$

equation 3

equation 4

Letting the Laplace transform be denoted by;

$$
\mathcal{L}\left[\frac{\mathrm{d}}{\mathrm{dt}} \mathrm{G}(\mathrm{t})\right]=\mathrm{s} \overline{\mathrm{G}},
$$

then equation 4 can be rewritten as shown below.

$$
s \overline{\mathrm{T}}_{\text {out }}+\frac{1}{\mathrm{AC}}\left(\overline{\mathrm{FT}}_{\text {out }}\right)=\frac{1}{\mathrm{C}} \overline{\mathrm{P}}_{\text {in }}+\frac{1}{\mathrm{AC}}\left(\overline{\mathrm{FT}}_{\text {in }}\right)
$$


If $\mathrm{F}$ is constant, or at least has small changes, then equation 5 may be simplified.

$$
\bar{T}_{\text {out }}=\overline{\mathrm{P}}_{\text {in }} \frac{\mathrm{A}}{\mathrm{F}} \frac{\omega_{\mathrm{O}}}{\mathrm{s}+\omega_{\mathrm{o}}}+\overline{\mathrm{T}}_{\text {in }} \frac{\omega_{\mathrm{O}}}{\mathrm{s}+\omega_{\mathrm{o}}}, \quad \omega_{\mathrm{o}}=\frac{\mathrm{F}}{\mathrm{AC}} \quad \text { equation } 6
$$

If Tin remains constant, Tout will change according to equation 7 below for a step change in Pin.

$$
\begin{aligned}
& \bar{P}_{\text {in }}=P_{\text {in }} \frac{1}{s} \\
& T_{\text {out }}(t)=P_{\text {in }} \frac{A}{F}\left(1-e^{-t \frac{F}{A C}}\right)
\end{aligned}
$$

equation 7

For the linac temperature control loop, Pin would represent the combination of if and water pump power. If Pin and the chilled water temperature are constant, and the chilled water flow is allowed to have only small changes, then equation 6 can be used to obtain an approximate response to a change in chilled water flow.

$$
\begin{array}{ll}
\frac{\bar{T}_{\text {out }}}{\bar{F}} \cong \frac{P_{\text {in }} A}{F^{2}} \frac{\omega_{0}}{s+\omega_{0}}=\frac{\Delta T}{A C} \frac{1}{s+\omega_{0}} & \\
\text { corner frequency } & \omega_{0}=\frac{F}{A C} \\
\text { unity gain frequency } & \omega_{u}=\omega_{0} \frac{P_{\text {in }} A}{F^{2}}=\frac{\Delta T}{A C} \\
\text { for steady state } & \Delta T=\left(T_{\text {out }}-T_{\text {in }}\right)=\frac{P_{\text {in }} A}{F}
\end{array}
$$

equation 8

equation 9

For a step change in flow of amplitude $F$, equation 7 provides an approximate time domain response. The frequency response described with equation 8 is that of a low pass filter with a single pole. The most notable characteristic is that the unity gain frequency is essentially constant for small changes in $\Delta \mathrm{T}$. The unity gain frequency is $670 \mu \mathrm{Hz}$ for $\Delta \mathrm{T}=14^{\circ} \mathrm{C}$. The corner frequency is about $67 \mu \mathrm{Hz}$ with the rf power on and $24 \mu \mathrm{Hz}$ with only the water pump power.

A set of five step response measurements were performed with a 16 accelerating cell section. The cavity temperature and resonant frequency were measured for one to two hours following a step change in chilled water flow. This data was then least squares fit to equation 7. Figure 5 was generated by changing the flow from .891 to $.477 \mathrm{gpm}$ and provides a typical example, both the data and the fit are shown. 


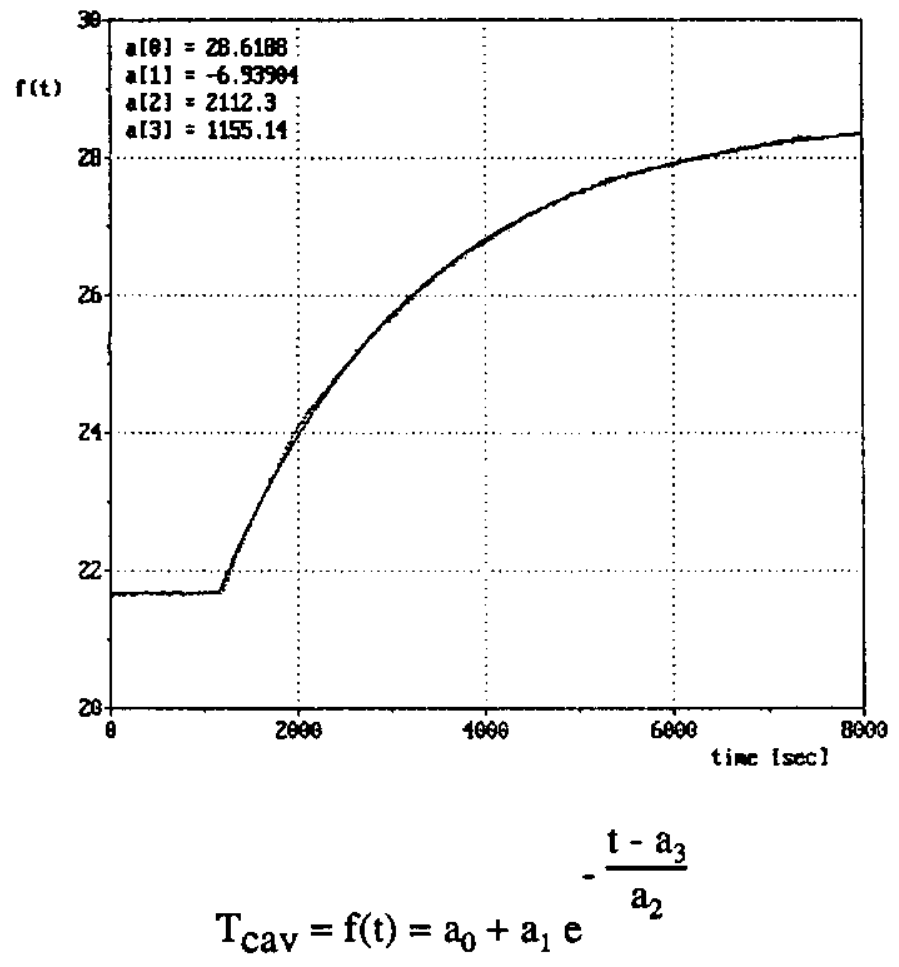

Figure 5. Cavity temperature change after a $-.414 \mathrm{gpm}$ step change in chilled water flow.

For the five different flow steps, the time constants, $a_{2}=A C / F$, were plotted versus $1 / F$ as shown in figure 6. The slope of the line indicated is for $\mathrm{C}=542 \mathrm{KJ} /{ }^{\circ} \mathrm{C}$. I believe the difference between the data points and the line is caused by violating the requirement of small flow changes of equation 6. 
page 12

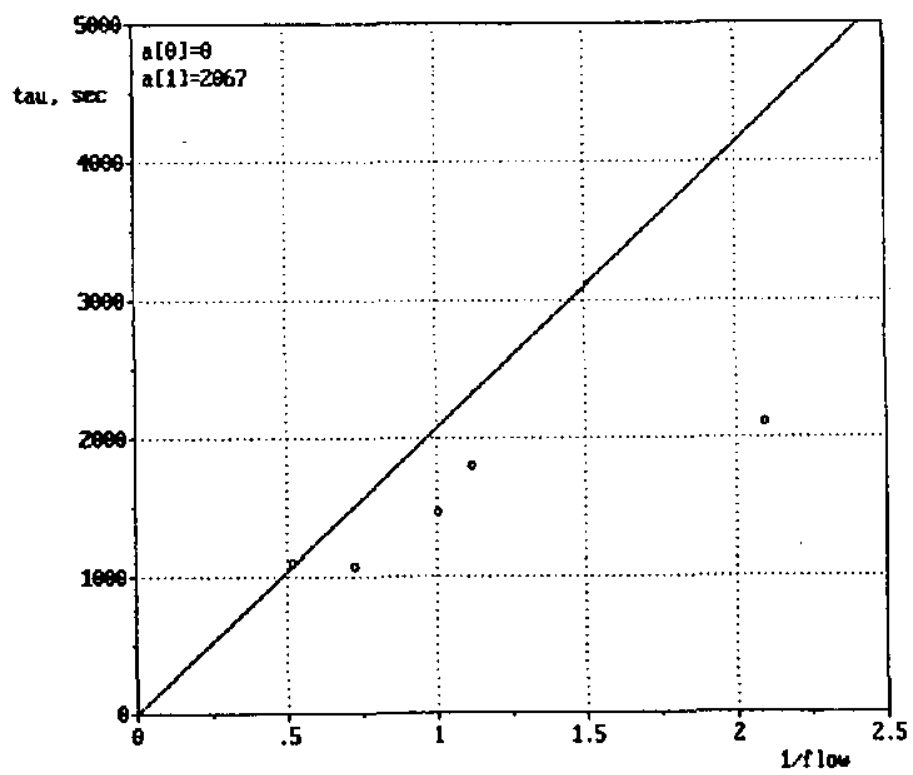

Figure 6. Measured time constant, $a_{2}=A C / F$, versus $1 / F$ for step changes in flow.

From figure 6 it can be seen that the measured step response fits the form of equation 7 very well. In addition, the agreement becomes exact in the steady state. Figure 6 indicates that for large changes in flow, the measured response is faster than predicted with equation 7 . Because the temperature feedback loop maintains a constant cavity temperature, equation 8 should be a good approximation to the open loop system response. Because the real response is faster than predicted, using equation 8 should provide a stable closed loop response.

Along with the above measurements, the steady state cavity temperature and the total power extracted from the system with the chilled water were recorded. The data points were least squares fit to a line as shown in figure 7 . The slope of 58.9 watts $/{ }^{\circ} \mathrm{C}$ is believed to be the radiation and convection losses of the cavity, cooling skid, and 98 feet of 1.5 inch diameter PVC pipe. The if and water pump power was $2.4 \mathrm{KW}$ which indicates the room temperature was about $27^{\circ} \mathrm{C}$. 


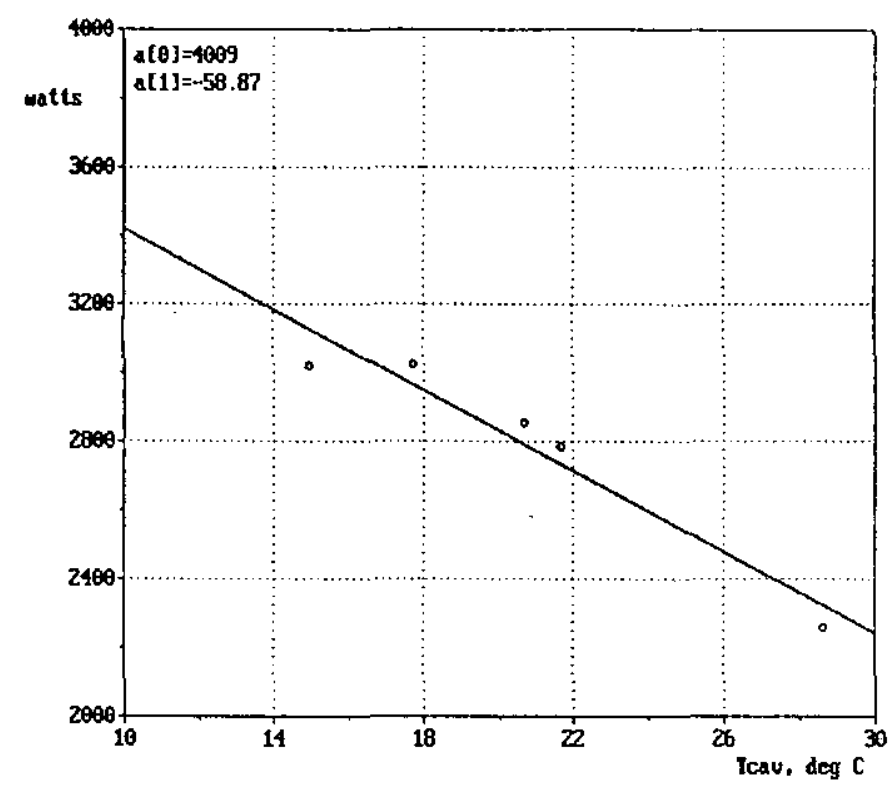

Figure 7. Required cooling power versus cavity temperature, input power is $2.4 \mathrm{KW}$.

\section{CLOSING THE LOOP:}

An integral type of controller was selected for the temperature loop because it has zero steady state error and because of its simplicity. Figure 8 provides a simple block diagram.

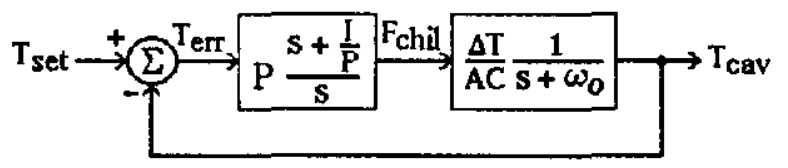

Figure 8. Simple block diagram of cavity temperature control loop.

If $\mathrm{I} / \mathrm{P}$ is chosen to equal $\omega_{0}=\mathrm{F} / \mathrm{AC}$, then the open loop response becomes a simple integrator. The unity gain frequency of the open loop will be the closed loop corner frequency, or closed loop bandwidth $\omega_{t}$, as indicated in equation 10 . The closed loop bandwidth will be essentially constant provided the cavity temperature changes are small.

$$
\frac{\bar{T}_{\text {cav }}}{\bar{T}_{\text {set }}}=\frac{\omega_{t}}{s+\omega_{t}} \quad \omega_{t}=P \frac{\Delta T}{A C}
$$


Theoretically the above system could have infinite closed loop bandwidth. Stability requires the open loop phase shift be less than $180^{\circ}$ at the unity gain frequency. A conservative design would have $45^{\circ}$ of phase margin, or only $135^{\circ}$ of phase shift. The open loop phase shift for the case above is $90^{\circ}$ for all frequencies. For the cavity loops, there will be additional phase shift caused by the thermal resistance of the film coefficient and the time required for the water to travel from the cooling skid to the cavity. As shown below, the closed loop bandwidth is limited to about $.001 \mathrm{~Hz}$.

$$
\begin{aligned}
& \text { For } \omega_{\mathrm{t}}=.001 \mathrm{~Hz} \quad 90.0^{\circ} \quad \text { controller integrator } \\
& 28.9^{\circ} \text { film coefficient, }(\tau=88 \mathrm{sec}) \\
& 9.7^{\circ} \quad \text { water travel time, }(27 \mathrm{sec}) \\
& \text { 2.6 } \text { control valve, }(\tau=7.3 \mathrm{sec}) \\
& 0.6^{\circ} \text { thermocouple amp, }(\tau=1.6 \mathrm{sec}) \\
& 0.4^{\circ} \quad \text { computer sample time. }(1 \mathrm{sec}) \\
& 132.2^{\circ} \text { Total phase shift }
\end{aligned}
$$

Experimentally it was found that $.0006 \mathrm{~Hz}$ closed loop bandwidth provided reasonable response, less than $10 \%$ overshoot, with the 16 accelerating cell section. An excellent agreement considering the uncertainty in the film coefficient.

In terms of system performance, larger closed loop bandwidths will reduce the effects of noise, or unpredictable disturbances, to the system. Using equation 9, the equivalent $\Delta F$ caused by changes in cavity temperature, chilled water temperature, or power can be found.

$$
\Delta F=\frac{A}{T} \Delta P_{\text {in }}=-\frac{P_{\text {in }} A}{T^{2}} \Delta T, \quad \text { for } T=\left(T_{\text {cav }}-T_{\text {chil }}\right) \quad \text { equation } 11
$$

These can be used in the following system response to predict cavity temperature errors.

$$
\frac{\bar{T}_{\text {cav }}}{\bar{F}}=\frac{1}{P} \frac{s \omega_{t}}{\left(s+\omega_{t}\right)\left(s+\omega_{0}\right)}
$$

equation 12

Figure 9 shows the calculated cavity temperature error generated with a $3.2 \mathrm{KW}$ step in power, or $.87 \mathrm{gpm}$ flow, at time $\mathrm{t}=0$. The $.4^{\circ} \mathrm{C}$ temperature error demonstrates the need for an accurate feedforward system. Note that the steady state error goes to zero. 


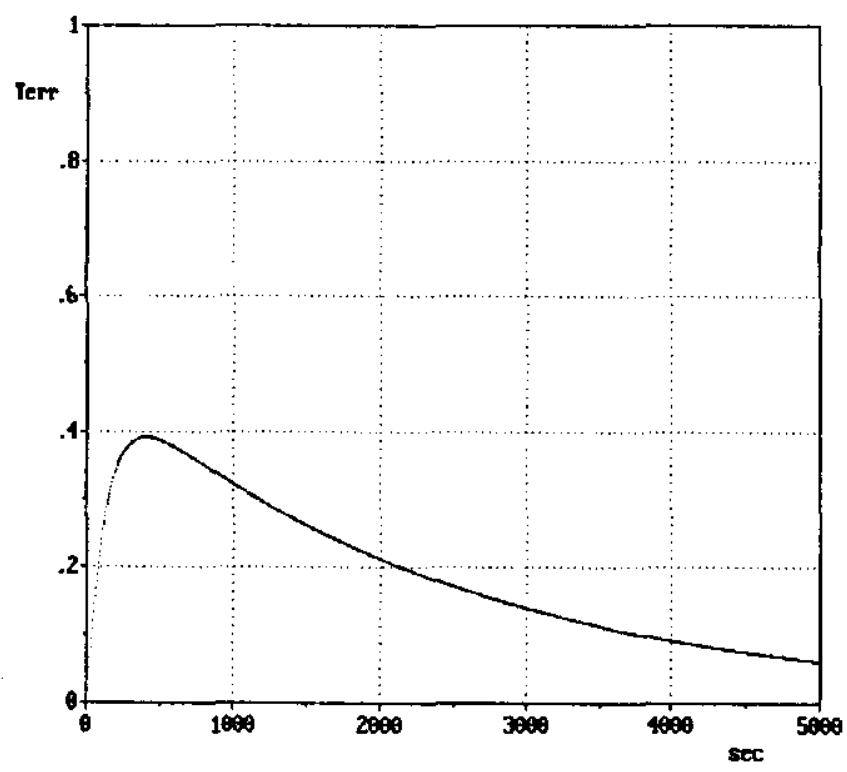

Figure 9. Cavity temperature error in response to a $3.2 \mathrm{KW}$, or $.87 \mathrm{gpm}$, step change.

Equation 11 can be used to implement a feedforward path in the loop. Since the if power, chilled water and cavity temperatures can be measured, they can be used to change the chilled water flow directly. In the simple model above, the errors could be completely eliminated. In the real system, the control accuracy of the chilled water flow and time delays, (as in the water circulation time or the time required for the cavity to reach equilibrium when the If power is changed), will limit the feedforward accuracy, particularly for transient changes.

To eliminate problems with linearity, hysteresis, and pressure induced errors in the control valve, a separate loop was implemented around the valve as indicated in figure 10.

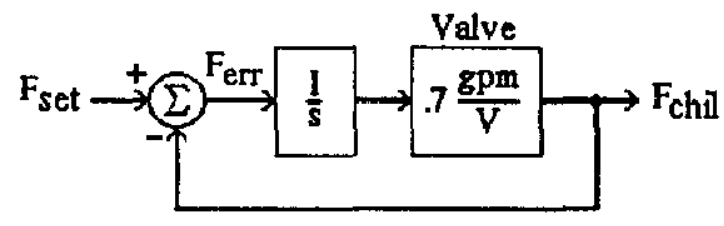

$$
\frac{\bar{F}_{\text {chil }}}{\bar{F}_{\text {set }}}=\frac{\omega_{\mathrm{f}}}{s+\omega_{\mathrm{f}}}, \quad \omega_{\mathrm{f}}=.7 \mathrm{I}
$$

Figure 10. Block diagram for chilled water flow control loop. 
Again, the bandwidth of the loop is limited by a delay time, the time required for the valve to change position. According to the Worcester specification, 15 seconds is required to move the valve from full closed to full open. In practice an adequate response was obtained with $\mathrm{I}=.2$ which provides a closed loop time constant of 7.3 seconds. The loop eliminated some cavity temperature variation caused by valve hysteresis and greatly improved the feedforward accuracy.

Because the cavities are not uniform in temperature with the of power applied, the placement of the temperature probes is critical. Currently it is planned to insert $1 / 8$ inch diameter thermocouple probes into a hole bored into the end cell at both ends of each section. One probe will regulate the temperature and the other will provide an independent monitor, or a spare if required. Ideally one would choose a point to monitor which does not change temperature when the If power is applied. Because the 265 second time constant of the temperature loop is so much larger than the 24 seconds required for the rf to heat the nose cones, the time required to reach equilibrium could be reduced if the system did not attempt to change the temperature of the $872 \mathrm{KJ} /{ }^{\circ} \mathrm{C}$ thermal mass. This could be accomplished artificially by providing a feedforward path from the measured if power to the cavity temperature set point. This could also compensate for any temperature differences between the end wall of the end cell and the cells in the middle of the section.

\section{IMPLEMENTATION:}

A block diagram of the system, as it will be implemented in the local controller, is shown in figure 11 below. The feedforward paths for both the rf power and chilled water temperature are included. Gain adjustments are provided to scale the peak if power into the average power per section. The water pump power is treated as a constant and can be used as the offset adjust for the power feedforward which can compensate for radiation and convection losses. In addition, provision has been made for the compensation of non uniform cavity temperature with a feedforward path between the if power and the set temperature. Table 3 provides a short description of the mnemonics used as well as the units of measure. Sorin Shtirbu has successfully implemented a version of the temperature control loop in the local computer.

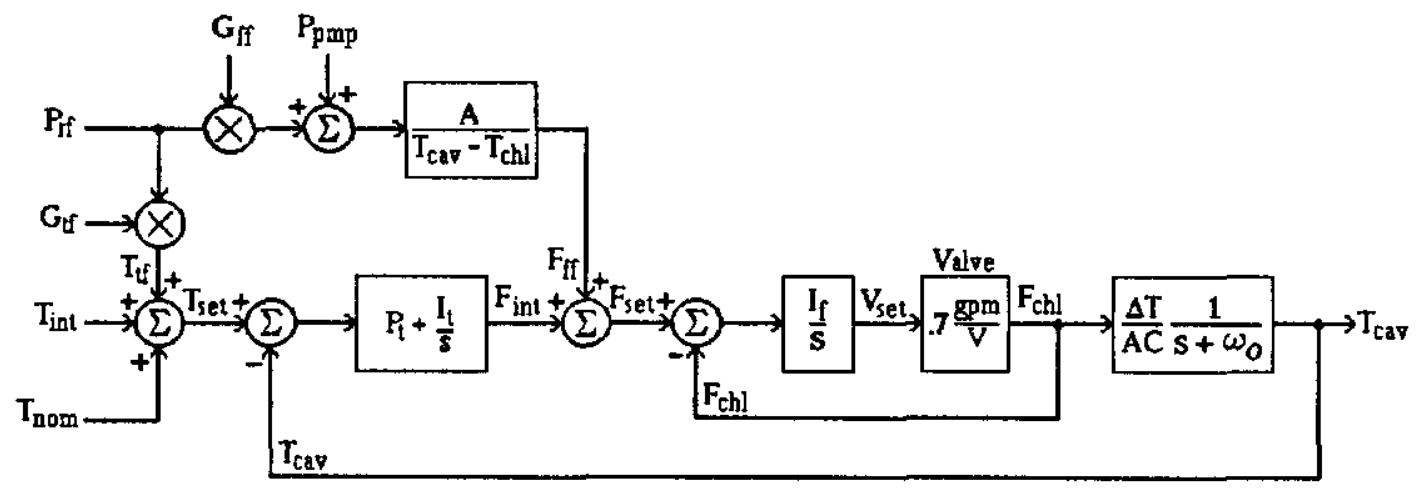

Figure 11. Block diagram of Temperature control loop. 


$\begin{array}{llll}\text { Table 3. } & \mathrm{T}_{\mathrm{cav}} & \text { Cavity temperature } & { }^{\circ} \mathrm{C} \\ & \mathrm{T}_{\text {set }} & \text { Temperature loop set point } & { }^{\circ} \mathrm{C} \\ & \mathrm{T}_{\text {nom }} & \text { Nominal cavity Temperature } & { }^{\circ} \mathrm{C} \\ \mathrm{T}_{\text {int }} & \text { Frequency loop integrator output } & { }^{\circ} \mathrm{C} \\ \mathrm{T}_{\mathrm{ff}} & \text { Feedforward temperature correction } & { }^{\cdot} \mathrm{C} \\ \mathrm{T}_{\mathrm{chl}} & \text { Chilled water temperature } & { }^{-} \mathrm{C} \\ \mathrm{F}_{\mathrm{int}} & \text { Temperature loop integrator output } & \mathrm{gpm} \\ \mathrm{F}_{\mathrm{max}} & \text { Temperature integrator limit } & \mathrm{gpm} \\ \mathrm{F}_{\mathrm{chl}} & \text { Chilled water flow } & \mathrm{gpm} \\ \mathrm{F}_{\mathrm{set}} & \text { Chilled water flow set point } & \mathrm{gpm} \\ \mathrm{F}_{\mathrm{ff}} & \text { Feedforward flow correction } & \mathrm{gpm} \\ \mathrm{V}_{\mathrm{set}} & \text { Valve control voltage } & \text { volts } \\ \mathrm{P}_{\mathrm{If}} & \text { Peak rf Power } & \mathrm{KW} \\ \mathrm{P}_{\mathrm{pmp}} & \text { Water pump power } & \mathrm{KW} \\ \mathrm{G}_{\mathrm{tf}} & \text { Temperature feedforward gain } & \\ \mathrm{G}_{\mathrm{ff}} & \text { Flow feedforward gain } & \\ \mathrm{P}_{\mathrm{t}} & \text { Temperature loop proportional gain } & \\ \mathrm{I}_{\mathrm{t}} & \text { Temperature loop integral gain } & \\ \mathrm{I}_{\mathrm{f}} & \text { Flow loop integral gain } & \\ \mathrm{L}_{\mathrm{cyc}} & \text { Number of clock cycles per loop } & 15 \mathrm{~Hz}\end{array}$

The $1 / \mathrm{s}$ terms in figure 11 represent integrals which are implemented in the code as summations of discrete variables as shown below.

$$
\frac{\mathrm{I}}{\mathrm{s}} \overline{\mathrm{T}}_{\mathrm{err}}(\mathrm{s}) \Leftrightarrow \mathrm{I} \int_{0}^{\mathrm{t}} \mathrm{T}_{\mathrm{err}}(\mathrm{t}) \mathrm{dt}=\mathrm{I} \Delta \mathrm{t} \sum_{\mathrm{m}=0}^{\mathrm{n}} \mathrm{T}_{\text {err }}(\mathrm{m}), \quad \text { for } \mathrm{t}=\mathrm{n} \Delta \mathrm{t}
$$

If for some reason the valve were disconnected or did not respond, the integrator would diverge to some large value. In order to minimize the time required to recover from such an occurrence, limits or clamps on the integrators are implemented in the code. The flow loop integrator is limited to be within the range of 0 to 10 volts and the temperature integrator is limited to 0 to Fmax gpm. It was observed that allowing large changes in chilled water flow induced cold pulses of water which caused the cavity temperature to oscillate as they circulated through the system. Limiting the maximum flow to $5 \mathrm{gpm}$ significantly reduced this problem. Currently $\Delta t$ is set to $8-15 \mathrm{~Hz}$ cycles.

The flow loop integrator is set with $\mathrm{I}_{\mathrm{f}}=.2$. This provides a closed loop bandwidth of .7 $\mathrm{I}_{\mathrm{f}} / 2 \pi=.022 \mathrm{~Hz}$, or a time constant of about 7 seconds. The temperature loop proportional gain, $P_{t}$, is set to .9 which provides a closed loop bandwidth of $P_{t} \Delta T / 2 \pi A C=.0006 \mathrm{~Hz}$. The 
temperature integrator gain, $I_{t}$, is set so that $I_{t} / P=\omega_{0}$ for the if power off condition, or $I_{t}=$ .0004 .

For testing purposes, one of the 16 accelerating cell sections was connected to the $2 \mathrm{MW}$ klystron and driven with an average power of about $2 \mathrm{KW}$. Rather than change the temperature to keep the cavity in tune, the drive frequency was phase locked to the cavity and the temperature loop was set to $20^{\circ} \mathrm{C}$. Figure 12 presents the results of running the cavity for almost four days. The measured cavity temperature was held to within $\pm .035^{\circ} \mathrm{C}$ and the resonant frequency to $\pm 550 \mathrm{~Hz}$. Since the noise level of the thermocouple amplifier is $\pm .025^{\circ} \mathrm{C}$ and the frequency structure of the measured temperature is much too fast to be real, I believe the actual cavity temperature error was much smaller than indicated. Likewise, the resonant frequency error of the cavity should be measured from the center of the high frequency noise in figure 12 making it about $\pm 300 \mathrm{~Hz}$. The $300 \mathrm{~Hz}$ error could be caused by a $.021^{\circ} \mathrm{C}$ temperature variation, a change in If power of 27 watts, or a phase measurement error of $85^{\circ}$ in the frequency loop. The fast variation in Prf of figure 12 is caused by droop in the diode peak detector between $15 \mathrm{~Hz}$ pulses of $\mathrm{rf}$. This can be overcome by using a sample and hold A/D channel in the rack monitor module.

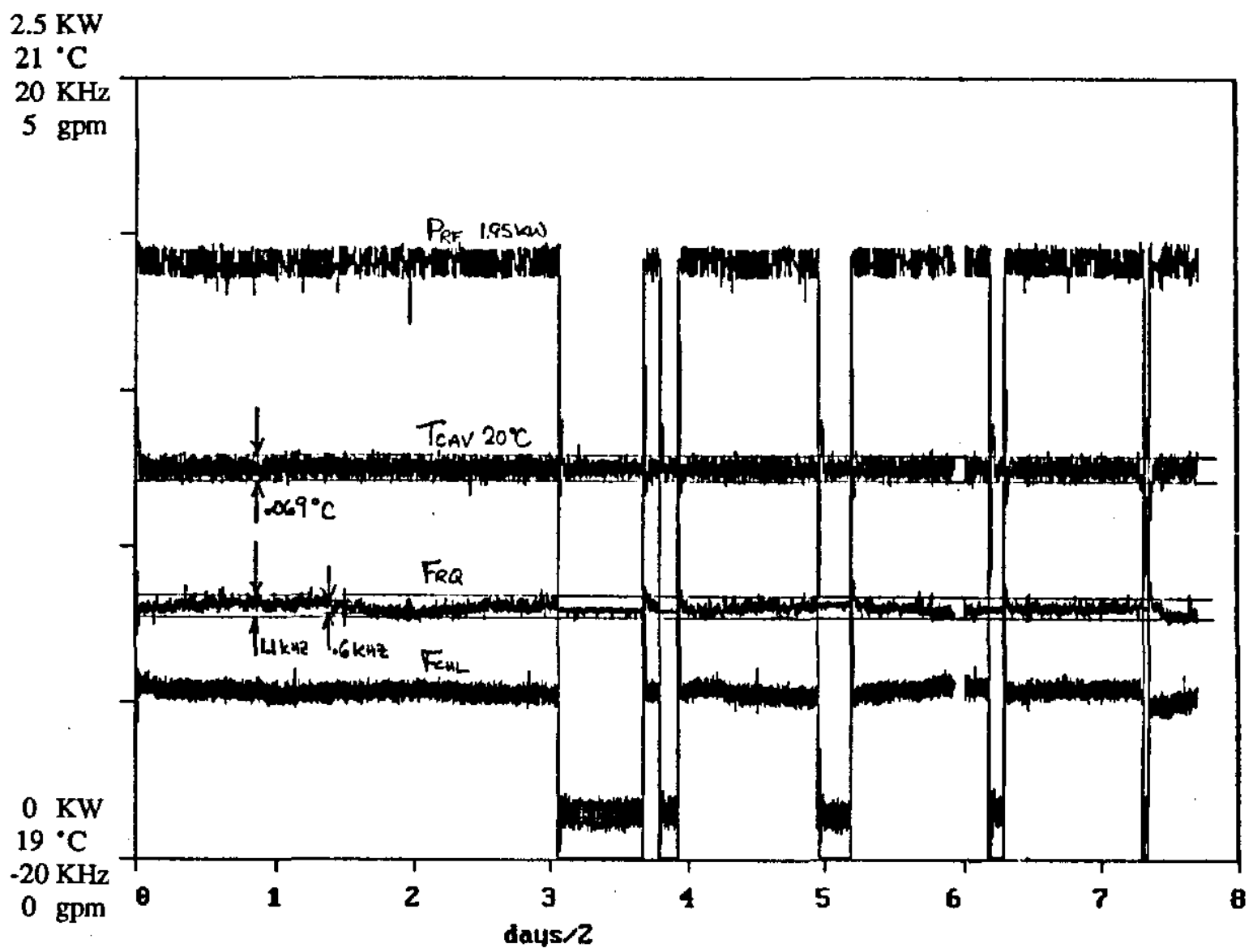

Figure 12. Temperature regulation of a 16 accelerating cell section. 
At times without $\mathrm{rf}$ power, the frequency loop was disabled and the last valid frequency was held. In reality, the resonant frequency of the cavity changes by $-11 \mathrm{KHz} / \mathrm{KW}$. Figure 13 shows the transient response to a step change in rf power of $2 \mathrm{KW}$. For this measurement the thermal capacity of the water and 16 accelerating cell section was $542 \mathrm{KJ} /{ }^{\circ} \mathrm{C}$ and the cavity water circulation time was about 30 seconds. The if power to chilled water flow feedforward was implemented but the temperature feedforward was not. The chilled water flow crosses the new steady state value in about 30 seconds, but the cavity continues to increase in temperature because it requires an additional 15 seconds for the water to travel from the cooling skid. The cavity temperature increases for about 70 seconds before it starts to decrease. The 25 second difference in time may be caused by the film coefficient of the cavity cooling tubes. The temperature error could be reduced with a derivative term in the power feedforward path, to compensate for the $1 /\left(\mathrm{s}+\omega_{0}\right)$ term, or by providing a feedforward signal preceding the actual change in power. The error would also be smaller if the if power were programmed on over a period of a minute as discussed previously.

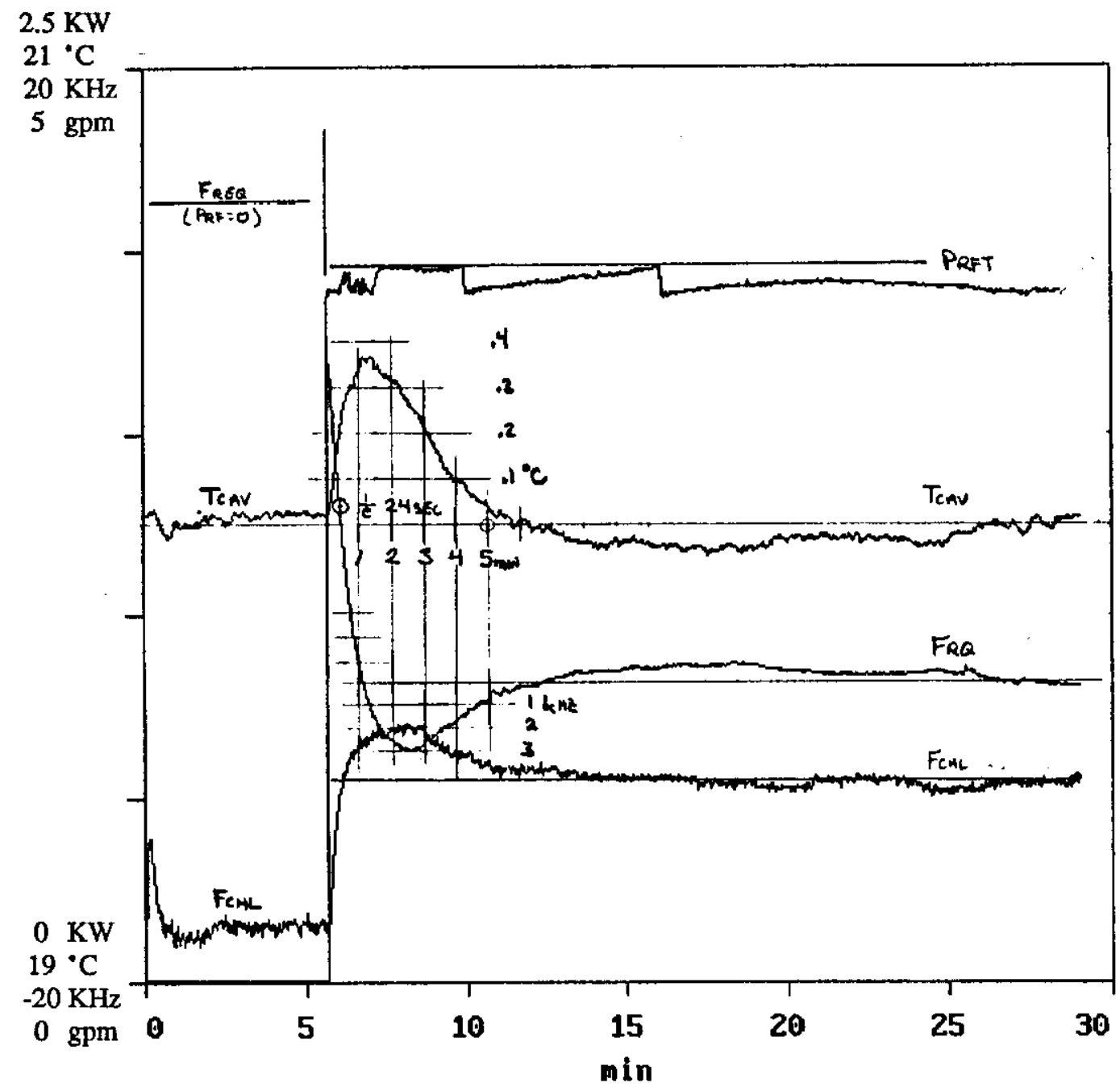

Figure 13. Transient temperature error caused by a $2 \mathrm{KW}$ step change in $\mathrm{rf}$ power. 
The frequency or phase loop can be implemented around the temperature loop as shown in figure 14 below. If $\mathrm{I} \phi / \mathrm{P} \phi$ is selected to equal $\omega t$, then the closed loop bandwidth will be 38.8 $\mathrm{P} \phi \omega t$. I suspect the largest stable value for $\mathrm{P} \phi$ will make the phase loop bandwidth equal to the temperature loop bandwidth. The 1/e time constant will be about 260 seconds.

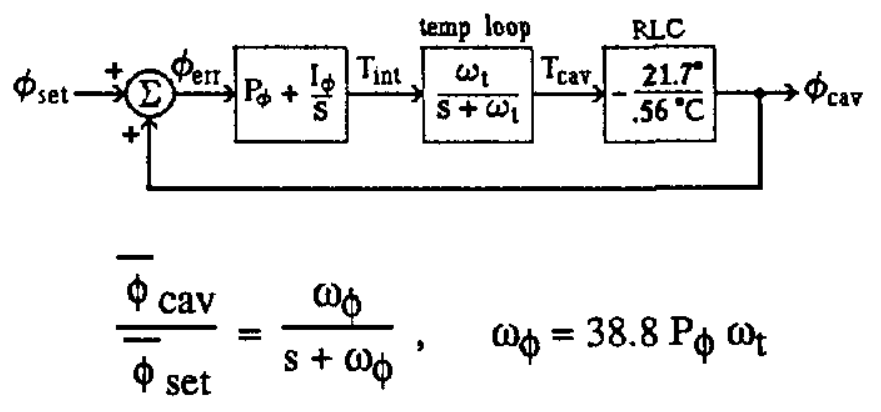

Figure 14. Block diagram of frequency control loop.

\section{CONCLUSION:}

Temperature loops have been implemented in the local computer for the 2 MW test station and have demonstrated a satisfactory performance even at the current level of development. The film coefficient of the cavity cooling tubes should be measured more accurately, however, to optimize the trade off between temperature loop bandwidth and cooling tube lifetime. In addition, the feedforward should be refined in order to reduce the transient temperature error caused by rf power changes. Depending on the effectiveness of feedforward on the transient errors, it may be desired to change the feedforward signal before changing the if power level.

It is interesting to note that the 24 second time constant associated with if heating of the nose cones, is three times faster than the film coefficient time constant and about equal with the time required for the water to flow from the cooling skid to the cavity. This implies that using the if to warm up the cavity noses is faster than anything which can reasonably be done to the water at the cooling skid.

The decision to run the cavities at or near room temperature has two major advantages. First, it reduces the effects of heat transfer through radiation and convection on the cooling system. Secondly, if the cooling system is turned off or fails, the cavity naturally stays near the nominal running temperature.

The frequency or phase control loop needs to be implemented in the local computer to allow the cavities to be driven with a fixed frequency. Because the thermal mass of the cavity is so large, it is impractical to change the temperature for short term changes in running conditions. The temperature should be set to the value which provides optimum performance for beam loaded conditions. The most difficult part of the frequency loop will be the decision process to 
determine that the phase error represents a stable beam current and operating condition and should be used to update the temperature loop set point.

Industrial chilled water at about $50^{\circ} \mathrm{F}$ will be passed through a heat exchanger to cool a common water system used by the cooling skids for the 28 cavity sections, 2 matching sections, and debuncher section. The temperature and differential pressure of this intermediate water system should be regulated, or controlled with feedback loops, to reduce the "source impedance". The transients induced in this system by turning on or off the rf power in one station may couple to other stations, possibly inducing oscillations. If the ff power is turned on simultaneously in all 30 cavity sections, then the required water flow through this intermediate system will change from 15 to $42 \mathrm{gpm}$ and the heat load will change from 51 to $147 \mathrm{KW}$.

\section{APPENDIX:}

Useful constants:

\begin{tabular}{|lccc|}
\hline & units & water & copper \\
\hline Density & $\mathrm{g} / \mathrm{cm}^{3}$ & .9971 & 8.96 \\
Specific Heat & $\mathrm{J} / \mathrm{g} \cdot{ }^{\circ} \mathrm{C}$ & 4.180 & .3866 \\
Conductivity & $\mathrm{W} / \mathrm{cm}-{ }^{\circ} \mathrm{C}$ & $6.09 \mathrm{e}-3$ & 3.98 \\
Expansion & $\mathrm{ppm} /{ }^{\circ} \mathrm{C}$ & & 16.5 \\
\hline
\end{tabular}

Conversion factors:

\begin{tabular}{|l}
1 calorie $=4.1840$ Joules \\
1 horse power $=745.8$ watts \\
1 pound $\quad=454$ grams \\
1 gallon $\quad=3.785 \mathrm{e}-3 \mathrm{~m}^{3}=231.0 \mathrm{in}^{3}$ \\
1 gallon water $=8.321 \mathrm{lbs}=3764$ grams, $\left(25^{\circ} \mathrm{C}\right)$ \\
1 Burger King whopper $=628 \mathrm{Kcal}=2628 \mathrm{KJ}$
\end{tabular}

Water cooling capacity:

$$
\frac{1 \mathrm{gal}}{3764 \mathrm{~g}} \frac{60 \mathrm{sec}}{\min } \frac{1 \mathrm{~g}^{\circ} \mathrm{C}}{4.180 \mathrm{~J}} \frac{1000 \mathrm{~J}}{\mathrm{KJ}}=3.814 \frac{\mathrm{gpm}-{ }^{\circ} \mathrm{C}}{\mathrm{KW}}
$$


Pump power, (100\% efficiency):

$$
\frac{4.448 \mathrm{NT}}{\text { pound }} \frac{231.0 \mathrm{in}^{3}}{\text { gallon }} \frac{1 \mathrm{~min}}{60 \mathrm{sec}} \frac{.0254 \mathrm{~m}}{\text { in }}=.4350 \frac{\text { watts }}{\mathrm{psi}-\mathrm{gpm}}
$$

Parameters for 1 section:

\begin{tabular}{|lcl|}
\hline Water capacity & 36 & gallons \\
Water circulation time & 54 & seconds \\
Film coefficient, (16 cells) & 3.4 & $\mathrm{KW} /{ }^{\circ} \mathrm{C}$ \\
Film coef. time constant & $\sim 88$ & seconds \\
Weight of copper & 1700 & pounds \\
Heat capacity, $\left(\mathrm{H}_{2} \mathrm{O}+\mathrm{Cu}\right)$ & 872 & $\mathrm{KJ} /{ }^{\circ} \mathrm{C}$ \\
Temperature Frequency shift & -14.3 & $\mathrm{KHz} / /^{\circ} \mathrm{C}$ \\
Power frequency shift & -11.0 & $\mathrm{KHz} / \mathrm{KW}$ \\
Power on freq time constant & 24 & seconds \\
Radiation and convection & 100 & watts/ $/{ }^{\circ} \mathrm{C}$ \\
Chilled water temperature & 11 & ${ }^{\circ} \mathrm{C}$ \\
Nominal cavity temperature & 25 & ${ }^{\circ} \mathrm{C}$ \\
\hline
\end{tabular}

\section{Control Valves:}

Control valves used for the chilled water flow have two major problems, nonlinearity and hysteresis. The Worcester brand valve can be purchased with different valve seat styles which change the flow versus valve rotation curves, or the linearity. The valve seats with the best linearity provide the least dynamic range. Low flow rates are the most difficult to control accurately because of hysteresis. The valve specification claims to have less than $.5 \%$ of span hysteresis. This turns out to be percent of valve positioner rotation not flow. The measured flow hysteresis was $2.3 \%$ of span. In addition, the flow is a function of pressure. The accuracy to which the flow can be set limits the use of feedforward in the system.

The Worcester valve can move from full open to full closed in about 15 seconds. This speed will limit the bandwidth of the chilled water flow loop. Currently the time constant for that loop is about 7.3 seconds, sufficiently small so as not to degrade the temperature loop. If other valves are used their speed should not be significantly slower.

\section{Flow meters:}

Turbine style flow meters are used for the chilled and cavity flow measurements. The cavity flow is expected to be a constant $40 \mathrm{gpm}$ and is only monitored to insure the system is functioning properly. The chilled water flow will vary from $.5 \mathrm{gpm}$ with the if off to $1.4 \mathrm{gpm}$ with the if on and may deviate from 0 to $5 \mathrm{gpm}$ as the loop corrects for transient changes. The chilled water flow signal is used to close a loop around the chilled water valve. The loop is used 
to improve the accuracy of setting the chilled water flow for the purposes of feedforward correction.

Standard turbine pickups induce drag on the turbine which limits the dynamic range of the flow to less than 10:1. Low drag pickups are used for the chilled water flow measurement which have a dynamic range of 100:1. The low drag pickup works by detecting the modulation of a $24 \mathrm{KHz}$ signal applied to the pickup induced by the turbine rotation. The model used has a .05 to $5 \mathrm{gpm}$ range and an accuracy of $.5 \%$ of span. A demodulation circuit was designed which transforms the low drag signal into pulses which can be used by the Tevatron style, 2 channel flow measurement cards. Both pickup styles can use the same turbine.

\section{Type J thermocouples:}

Type $\mathrm{J}$ thermocouples were selected for their large Seebeck coefficient, $51.70 \mu \mathrm{volt} /{ }^{\circ} \mathrm{C}$ at $25^{\circ} \mathrm{C}$, and the availability of thermocouple amplifiers with a solid state cold junction reference, Analog Devices AD594. The type J junction consists of iron and constantan. One advantage is that the iron lead can be readily identified with a magnet, the disadvantage is that it can oxidize.

If the iron constantan leads are reversed at a connector it can be difficult to diagnose. Because the two thermocouple joints thus formed are in series with opposite polarity, their voltages will exactly cancel if they are at the same temperature. Unfortunately, room temperature changes will heat the junctions unevenly and cause their temperatures to differ. A reversed junction in the linac gallery had a room temperature induced error of $\pm .5^{\circ} \mathrm{C}$ over the course of a few hours.

In the thermocouple amplifier modules designed for the linac, a $.1 \mathrm{~Hz} 2^{\text {nd }}$ order low pass filter was included to reduce noise. With the filter, the noise level is equivalent to $\pm .025^{\circ} \mathrm{C}$. This seems to be caused by $1 / \mathrm{f}$ noise in the thermocouple amplifier. The $.1 \mathrm{~Hz}$ corner frequency should be high enough in frequency to avoid significant delay in the temperature loops, which have a closed loop bandwidth of $.0006 \mathrm{~Hz}$. The $.0006 \mathrm{~Hz}$ bandwidth of the temperature loop has the effect of filtering the thermocouple noise even further. As a result, the actual cavity temperature is regulated much better than the $.025^{\circ} \mathrm{C}$ figure. The amplifiers will be calibrated for a range of 0 to $50^{\circ} \mathrm{C},\left(32\right.$ to $\left.122^{\circ} \mathrm{F}\right)$, for an output range of -10 to +10 respectively. Combined with the 12 bit $A / D$ converter in the rack monitor module, this range will provide a resolution of $.0122^{\circ} \mathrm{C} / \mathrm{bit}$.

The Analog Devices AD594 thermocouple amplifier has a temperature stability of \pm .025 ${ }^{\circ} \mathrm{C} /{ }^{\circ} \mathrm{C}$ and an accuracy of $\pm 1{ }^{\circ} \mathrm{C}$. The accuracy is limited by the linearity of the Seebeck coefficient of type $J$ thermocouples.

The ANSI specification for type $\mathrm{J}$ thermocouple accuracy between 0 and $277^{\circ} \mathrm{C}$ are \pm 2.2 ${ }^{\circ} \mathrm{C}$ for the standard limits of error and $\pm 1.1^{\circ} \mathrm{C}$ for the special limits of error. As a consequence, in order to make an absolute temperature measurement, both the thermocouple amplifier and junction must be calibrated together, and the changes with temperature of the Seebeck coefficient must be accounted for. For the linac temperature loop, the cavity resonant frequency 
has the ultimate control over its set point. All that is required of the temperature calibration is that it remain stable over the length of time required for the frequency loop to acquire a stable temperature set point.

An Omega CL23 digital thermometer calibrator was purchased to calibrate the thermocouple amplifiers. It has an accuracy of $\pm .6^{\circ} \mathrm{C}$ and a repeatability of $\pm .2^{\circ} \mathrm{C}$. The CL23 takes into account the changes of Seebeck coefficient with temperature. The thermocouple amplitier will be calibrated with the CL23 at 0 and $50^{\circ} \mathrm{C}$. Changes in the Seebeck coefficient will give a temperature error of $.04^{\circ} \mathrm{C}$ within this range.

Currently it is planned to use thermocouples sheathed within a $1 / 8$ " diameter inconel tube and placed inside a hole bored into each end of a cavity section. It is very important to insure good thermal connection between the end of the probe and the walls of the cavity hole. The thermal time constant for the ungrounded probe in water is .53 seconds. The time constant for the same probe in air flowing at $65 \mathrm{ft} / \mathrm{sec}$ becomes 20.1 seconds, a significant delay for the temperature control loop.

\section{Linac water system downtime:}

The existing linac temperature control system uses a chilled water valve to control the cavity water temperature similar to what is proposed for the linac upgrade. I have examined the accelerator downtime contributed by the linac cavity water system for the last 4 years. Out of a total operating time of 26368 hours the water system contributed 17.86 hours of downtime. There were 107 entries 80 of which were caused by the cavity water pump tripping off which contributed 8.45 hours. Water leaks and changing or repairing water pumps contributed 6.10 hours. Jeff Meisner indicated that, according to his memory, about 1 chilled water valve per year is replaced or repaired. Apparently the failure consists of a leaky valve which does not impair operation and can therefore be replaced during a normal maintenance period.

If reducing downtime is of concern, I would recommend being frugal in selecting which things can trip off the cavity water pump. From the downtime log, the average time attributed to a pump trip was 6.3 minutes. This reflects the fact that the pump requires a local start command. 